\title{
Botulinum Toxin Type A for Pain in Advanced Parkinson's Disease
}

\author{
Veronica Bruno, Maria Eliza Freitas, Deborah Mancini, Jane P. Lui, \\ Janis Miyasaki, Susan H. Fox
}

\begin{abstract}
Background and Objective: Pain is a frequent symptom in Parkinson's disease (PD), and the therapeutic alternatives are scarce. The goal of this trial was to measure the effects of botulinum toxin type A (BTXA) in the treatment of limb pain in advanced PD. Methods: A randomized double-blind crossover versus placebo study of BTXA for limb pain in advanced Parkinson's disease was conducted. Subjects received individualized BTXA/placebo dosing per pain distribution in limbs. The primary outcome was a measure of change in global pain on a numeric rating scale (NRS) at 4 and 12 weeks postinjection and on a visual analogue scale 12 weeks after treatment. Secondary outcomes included the percentage of responders, physician-rated clinical global impressions, MDS-UPDRS and PDQ-39 scores, and adverse events. Results: A total of 12 subjects completed the trial. Treatment with BTXA (average dose $=241.66$ U) produced a significant reduction in NRS score 4 weeks after the injections $(-1.75$ points, range from -3 to $7, p=0.033)$. However, there was no significant difference compared to placebo $(p=0.70)$. Participants with dystonic pain showed a greater reduction in NRS score after 4 weeks when treated with BTXA $(2.66$ points vs. 0.75 for placebo). There were no significant differences for any of the secondary outcomes or significant adverse events. Conclusions: Targeted BTXA injections were safe in patients with limb pain and advanced PD; however, the present study failed to show a significant effect when compared to placebo. Further studies may be focused on evaluating the effect of BTXA particularly in dystonic pain.

RÉSUMÉ: Utilisation de la toxine botulique de type A pour soulager la douleur de sujets au stade avancé de la maladie de Parkinson. Contexte et objectifs: Ressentir de la douleur demeure un symptôme fréquent de la maladie de Parkinson. Cela dit, les solutions thérapeutiques continuent à être limitées. L'objectif de cet essai clinique a donc été de mesurer les effets de la toxine botulique de type A en ce qui regarde le soulagement de la douleur aux membres chez des sujets au stade avancé de la maladie de Parkinson. Méthodes: Nous avons mené une étude randomisée et croisée à double insu, contrôlée par placebo, au sujet de l'efficacité de la toxine botulique de type A dans le soulagement de la douleur. On a ainsi administré à nos sujets une posologie individualisée de toxine botulique de type A ainsi qu'un placebo en fonction de la distribution de la douleur à leurs membres. Le principal indicateur mesuré a porté, 4 et 12 semaines après les injections, sur les changements de scores obtenus sur l'échelle numérique de la douleur et, 12 semaines plus tard, sur l'échelle visuelle analogique. D'autres indicateurs secondaires ont également été mesurés : le pourcentage d'intervenants impliqués, les impressions cliniques d'ensemble de médecins, l'échelle d'évaluation unifiée de la maladie de Parkinson de la Movement Disorder Society, les scores obtenus au PDQ-39 et la fréquence d'évènements indésirables. Résultats: Au total, 12 sujets ont complété cet essai clinique. L'administration de toxine botulique de type A (dose moyenne $=241,66 \mathrm{U}$ ) a produit, 4 semaines après les injections, une réduction importante des scores obtenus sur l'échelle numérique d'évaluation de la douleur $(-1,75$ points ; écart de -3 à $7 ; p=0,033)$. Cela dit, aucune différence notable n'a été observée par rapport au placebo $(p=0,70)$. Chez les sujets souffrant de douleurs d'origine dystonique, on a pu observer, 4 semaines après les injections, la plus grande réduction des scores obtenus sur l'échelle numérique d'évaluation de la douleur (2,66 points contre 0,75 pour le placebo). Fait à noter, on n'a observé aucune différence notable quant aux indicateurs secondaires énumérés ci-dessus ou en ce qui regarde des évènements indésirables. Conclusions: Les injections ciblées de toxines botuliques de type A se sont avérées sans danger dans le cas de sujets au stade avancé de la maladie de Parkinson souffrant de douleurs aux membres. La présente étude n'a toutefois pas été en mesure de révéler un effet notable des toxines botuliques de type A après comparaison avec un placebo. Cela étant, il se peut que des études ultérieures se penchent sur les effets de ces toxines, en particulier en ce qui regarde les douleurs d'origine dystonique.
\end{abstract}

Keywords: Parkinson's disease, Pain, Botulinum toxin, Palliative, Dystonia

doi:10.1017/cjn.2017.245

Can J Neurol Sci. 2018; 45: 23-29

\section{INTRODUCTION}

Pain is a frequent symptom in Parkinson's disease (PD) that has gained increased recognition during the last decade. ${ }^{1}$ It is a very prevalent symptom (from 40 to $80 \%$ in different series), and in many patients pain is so severe and intractable that it overshadows the motor symptoms of the disorder. ${ }^{2,3}$ Additionally, as the disease progresses, pain can represent considerable illness burdens associated with reduced health-related quality of life, and symptom relief becomes the treatment goal. ${ }^{4-6}$ Classically, PD-related pain was classified as one of five categories: musculoskeletal pain, neuritic or radicular pain, dystonia-associated pain, primary or central pain, and akathitic discomfort. ${ }^{7,8}$
Musculoskeletal (reported in $70 \%$ of patients) and dystonic (reported in $40 \%$ ) pain are the most frequent types. ${ }^{2}$

From the Morton and Gloria Shulman Movement Disorders Clinic and the Edmond J. Safra Program in Parkinson's Disease, Toronto Western Hospital, University Health Network, Toronto, Ontario, Canada (VB, MEF, DM, SHF); Toronto Western Hospital, University Health Network, Toronto, Ontario, Canada (JPL); the Department of Neurology, University of Alberta, Edmonton, Alberta, Canada (JM). Received March 22, 2017. Final Revisions Submitted July 9, 2017. Date of ACCEPTANCE July 16, 2017.

Correspondence to: Veronica Andrea Bruno, Toronto Western Hospital, 399 Bathurst Street, 7th Floor, McLaughlin Pavilion, Toronto, Ontario, Canada, M5T.

Email: veubru@gmail.com 
The most challenging aspect of pain in PD is the scarcity of effective treatments. ${ }^{7-9}$ Limited evidence supports the use of duloxetine, ${ }^{10}$ rotigotine, ${ }^{11}$ and subthalamic nucleus (STN) or pallidal deep brain stimulation (DBS) as effective treatment options for pain in PD. ${ }^{12,13}$ Oxycodone/naloxone prolongedrelease tablets trials failed to improve outcomes in this group of patients. ${ }^{14}$ In addition, many of the frequently used treatments for pain can exacerbate PD symptoms (including constipation, hallucinations, and confusion) that are common in the advanced stages of PD, and most of the patients in the later stages of the disease are not candidates for surgical treatment. ${ }^{6}$

Botulinum toxins (BTXs) are an effective treatment modality for a growing number of indications in neurology, including dystonia, spasticity, and headaches. ${ }^{15}$ In clinical practice, BTX has been used "off-label" in PD for similar issues such as dystonia and rigidity in advanced PD. ${ }^{16}$ In our clinical experience, evaluated retrospectively, most of the PD patients that received injections with botulinum toxin type A (BTXA) for pain in the limbs reported a significant benefit that was sustained over time with almost no adverse effects (AEs). ${ }^{17}$ However, there is a large placebo effect in PD. To date, prospective randomized placebocontrolled trials using BTXA for this indication in PD have not been performed.

We hypothesize that BTXA can be a useful treatment for limb pain in advanced PD when lack of response to regular analgesic drugs and the AEs related to opioids significantly reduce the treatment options. The goal of this trial was to perform a doubleblind randomized placebo-controlled crossover trial to measure the effects of BTXA in the treatment of limb pain in advanced PD.

\section{Methods}

\section{Study Design}

The study was conducted between November of 2014 and December of 2015 at the Toronto Western Hospital Movement Disorders Center. We conducted a randomized double-blind crossover placebo-controlled trial. Subjects, caregivers, and clinic investigators were blinded as to assignment.

\section{Participants}

Males and females older than 30 years of age with idiopathic PD as per the UK Brain Bank criteria ${ }^{18}$ were candidates to participate in the study. The inclusion criteria were as follows: (1) subjects with advanced PD (Hoehn and Yahr 3-5, including post-STN DBS) and painful limbs not responding to antiparkinsonian agents according to subjective assessment (patients with OFF dystonia pain with response to levodopa were not included); (2) botulinum toxin treatment-naïve subjects or had not received any within the previous 12 months (for any indication); (3) stable PD and pain medications, and stable DBS settings for at least 30 days; and (4) competence to self-report pain severity using a numeric rating scale (NRS) and a visual analogue scale (VAS). ${ }^{19}$ Patients who required a translator or were unable to read were included if they could self-report pain severity on an NRS and a VAS. The exclusion criteria included the following: (1) subjects with a primary cause of pain unrelated to PD and associated with another medical condition (e.g., severe arthritis); (2) subjects that because of the severity or refractory nature of the pain are using an unfixed analgesic schedule; (3) subjects unable to self-report pain severity on an NRS or VAS; (4) subjects with any unstable medical condition; and (5) any contraindication to receiving BTX injections, including hypersensitivity to any ingredient in the formulation or component of the container (Clostridium botulinum toxin type A neurotoxin complex $900 \mathrm{kD}$, human serum albumin, and sodium chloride) or the presence of infection at the proposed injection site(s).

\section{Outcomes and Clinical Assessments}

The primary outcome was a measure of global pain as perceived by the patients assessed by: (1) a change in pain on an NRS administered during a phone interview at 4 weeks postinjection between BTXA and placebo injections; and (2) a change on the NRS and VAS (Edmonton Symptom Assessment System numerical scale) after 12 weeks between BTXA and placebo.

Secondary outcomes included: percentage of responders, defined as those who had at least a 2-point reduction on the NRS or a $20-\mathrm{mm}$ reduction on the VAS; physician-rated Clinical Global Impression (CGI); MDS Unified Parkinson Disease Rating Scale (MDS-UPDRS, parts I-III) ON-levodopa; quality of life by Parkinson Disease Questionnaire (PDQ-39) between baseline and 12 weeks; and adverse events as assessed at each study visit.

The protocol included a screening visit (weeks -2 to 0 ), three visits to the clinic, and two telephone interviews. During screening visits, written informed consent was obtained, and the inclusion and exclusion criteria were reviewed. A complete medical and neurological history and examination were performed. Parkinsonian disability was assessed using the MDS-UPDRS. Localization of the pain was recorded descriptively using a pictorial body chart. Suitable subjects were randomized using computer-generated randomization tables (generated by the hospital pharmacy) to BTXA or placebo at first injection, and crossover to placebo or BTXA at the second injection after 12 weeks. During visit 2 (week 0) and visit 3 (week 12), injections were performed into painful limbs under electromyographic (EMG) guidance as per the crossover design. NRS, VAS, ON-levodopa MDS-UPDRS, CGI, and PDQ-39 were completed. Subjects were asked about adverse events in detail. During telephone follow-up interviews 1 (at week 4) and 2 (at week 16), NRS and AEs were assessed. The times were selected to be coincident with the peak effect of BTXA treatment (4 weeks postinjection) and the duration of effect at 12 weeks according to average duration of BTXA injections and use in previous clinical trials. $^{20-22}$

During visit 4 (week 24), subjects were evaluated using the MDS-UPDRS, CGI, and PDQ-39, completed the NRS and VAS before the injections, and were asked about adverse events. The total duration of participation for each subject was 24-26 weeks.

During the trial, participants could take their parkinsonian (levodopa, dopamine agonists, cathecol-o-methyltransferase inhibitors, monoamine oxidase inhibitors, etc.) and pain medications (antiinflammatory drugs, opioids, gabapentin, etc.) but were asked to keep to a stable dose during the study. No changes in DBS stimulation were performed in those participants undergoing that treatment.

\section{Study Design and Treatment Administration}

Eligible subjects were randomized to receive either BTXA injections or placebo on visit 2 in a double-blind manner according to the randomization schedule. The subjects were crossed over to 
receive the other treatment (placebo or BTXA injections, respectively) after 12 weeks (visit 3). BTXA preparation was performed by the pharmacist, who assigned serial numbers to the placebo- or BTXA-containing vials. BTXA or normal saline $0.9 \%$ (placebo) were injected under EMG guidance, as per the usual standard of care. The study investigator and patient were blinded to injection assignment. An individualized dose was injected in the painful limbs: up to 200 units in the upper limbs or up to 300 units in the lower limbs according to the average doses that subjects with PD pain in the limbs received in our clinic, as per our retrospective study. ${ }^{17}$ Each injection contained 25 units of BTXA, and the number of injections ranged from 1 to 8 for the upper limbs and from 1 to 12 in the lower limbs. The pattern of injections was decided by the study investigator according to localization of pain and was the same pattern and dose for each individual patient at both injection visits (visits 2 and 3 ).

\section{Statistical Analysis}

For the primary outcome measure, the NRS, the change between baseline (time of injection) and at 4 weeks postinjection (peak effect) was compared between BTXA and placebo. The change in NRS and VAS scores between baseline (time of injections) and 12 weeks postinjection was compared between the BTXA and placebo groups. The secondary outcomes included change in CGI; ON-levodopa MDS-UPDRS (parts I, II, and III); percentage of responders on the NRS; and PDQ-39 between baseline and 12 weeks postinjection; and were compared for BTXA versus placebo. Categorical data were evaluated using Wilcoxon's signed-rank test. Paired $t$-tests were performed to compare mean values for quantitative data. Regression analysis was performed for age, sex, disease duration, levodopa equivalent daily dosage (LEDD), DBS treatment, MDS-UPDRS scores (parts I, II, and III) as covariates. The frequency of adverse events between the BTXA and placebo groups was compared using a $\chi^{2}$ analysis. Statistical significance was set at $p<0.05$. Statistical analysis was performed using Stata software (v. 13.0; StataCorp, College Station, TX).

Power analysis showed that using a mean value of 6 points on the NRS and an expected reduction of 2 points, with a standard deviation $(S D)$ of 1 point, the number of subjects to treat is 11 subjects with a power of $95 \%$. Similar analyses were performed for all secondary outcomes, showing that a sample size from 10 to 12 participants was adequate to detect differences of at least $20 \%$ in response between groups. With an expected dropout rate of 10-20\%, 12-14 patients were recruited.

\section{Standard Protocol Approval Registrations, and Patient Consents}

Approval was obtained from the relevant human research ethics committee and Health Canada. Informed consent was obtained from all participants. The study was registered on www. clinicaltrials.gov as no. NCT02472210.

\section{RESUlts}

\section{Participant Characteristics}

A total of 14 subjects were included. Recruitment and allocation are summarized in Figure 1. Two subjects were excluded prior to randomization. One patient decided to withdraw due to complications related to motor symptoms of the disease, and one

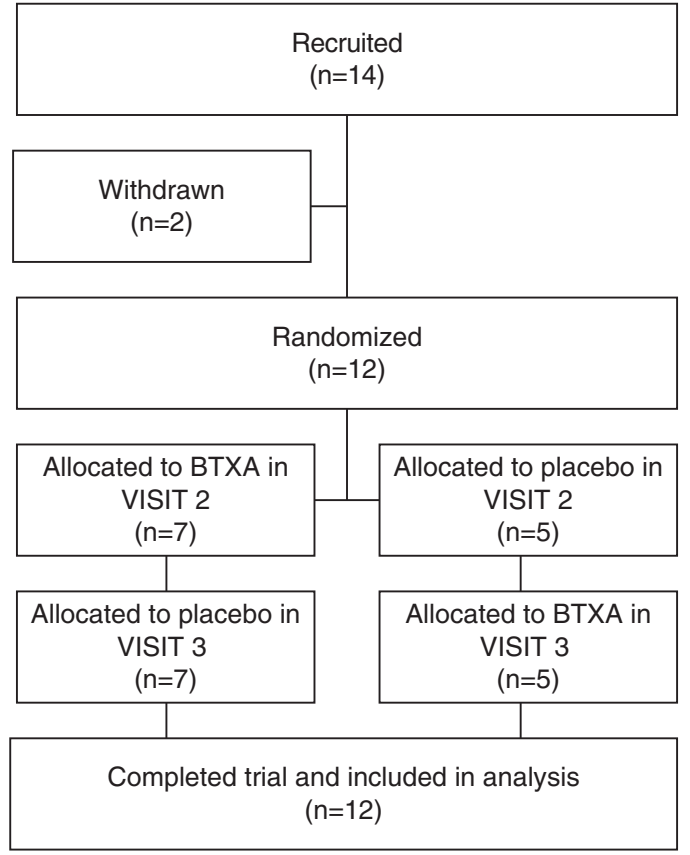

Figure 1: Study recruitment and allocation flowchart.

was excluded after it was determined that there was a clear clinical explanation for the limb pain (trophic changes in the skin compatible with peripheral vascular disease). Patient characteristics are summarized in Table 1. A total of 12 subjects completed the trial, 8 of whom were male $(66.6 \%)$. The mean age was 65.83 years $(S D=9.93)$, and the mean disease duration was 14.83 years $(S D=6.40)$. Four had prior DBS treatment (between 6 months and 1 year prior to the study). Half of the patients had symptoms compatible with musculoskeletal pain and the other half with dystonic pain. The mean injected dose of BTXA was 241.66 units $(S D=89.88$, range $=125-400$ units $)$.

One participant had received prior BTXA more than a year before the study to treat blepharospasm and sialorrhea.

\section{Primary Outcomes}

\section{Change in Pain Scores (NRS) at 4 Weeks (Peak Effect) and (NRS and VAS) at 12 Weeks Four weeks after injections}

Treatment with BTXA produced a significant reduction in NRS 4 weeks after injections (1.75 points, range from -3 to 7 , $p=0.033$ ). There was no significant effect of placebo injections in the NRS change (1.17 points, range from -4 to $5, p=0.17)$. However, when comparing BTXA with placebo, there was no significant difference on the NRS $(p=0.70)$ (Table 2).

Subgroup analysis of participants with dystonic pain $(n=6)$ showed a greater reduction on the NRS after 4 weeks when treated with BTXA (2.66 points vs. 0.75 for placebo) than participants with musculoskeletal pain (1.41 points vs. 0.83 for placebo). However, this difference was not statistically significant $(p=0.32)$.

\section{Twelve weeks after injections}

There were no significant differences between change in pain on the NRS for those patients treated with BTXA ( 0.87 points, 


\section{Table 1: Participants characteristics}

\begin{tabular}{l|c}
\hline Age, mean years $\pm S D$ & $65.8 \pm 9.9$ \\
\hline Female sex, $n(\%)$ & $4(33.3)$ \\
\hline Disease duration, mean years $\pm S D$ & $14.8 \pm 6.4$ \\
\hline LEDD, ${ }^{*}$ mean mg/day $\pm S D$ & $925.8 \pm 420.7$ \\
\hline MDS-UPDRS (ON-levodopa) at baseline, mean $\pm S D$ \\
\hline MDS-UPDRS I & $15.91 \pm 8.82$ \\
\hline MDS-UPDRS II & $18.08 \pm 11.20$ \\
\hline MDS-UPDRS III & $29.91 \pm 13.13$ \\
\hline Prior DBS, $n(\%)$ & $4(33.3)$ \\
\hline Prior use of BTXA & $1(8.33)$ \\
\hline Indication: & Blepharospasm and sialorrhea \\
\hline Type of pain, $n$ (\%) & \multicolumn{2}{|c}{} \\
\hline Musculoskeletal & $6(50)$ \\
\hline Dystonic & $6(50)$ \\
\hline Predominant location of pain, $n(\%)$ & $2(16.6)$ \\
\hline Unilateral upper limb & $3(25)$ \\
\hline Unilateral lower limb & $2(16.6)$ \\
\hline Bilateral upper limbs & $2(16.6)$ \\
\hline Bilateral lower limbs & $3(25)$ \\
\hline Unilateral upper and lower limb & 241.66 \\
\hline Average dose of BTXA (units) & \\
\hline
\end{tabular}

*Source: Tomlinson CT, Stowe R, Patel S, Rick C, Gray R, Clarke CE. Systematic review of levodopa dose equivalency reporting in Parkinson's disease. Mov. Disord. 2010;25:2649-53.

BTXA = botulinum toxin type A; DBS = deep brain stimulation;

LEDD = levodopa equivalent dose MDS-UPDRS = Movement Disorder Society Unified Parkinson's Disease Rating Scale (I: Non-Motor Aspects of Experiences of Daily Living; II: Motor Aspects of Experiences of Daily Living, III: Motor examination); $S D=$ standard deviation.

$p=0.35)$ or placebo (0.79 points, $p=0.32)$. Comparing BTXA versus placebo, there were no significant differences $(p=0.88)$ (Table 2). In addition, there were no significant differences between change in pain using the VAS in those patients treated with BTXA (7.63 mm, $p=0.23)$ or placebo $(6.33 \mathrm{~mm}, p=0.44)$. Comparing BTXA and placebo, there were no significant differences $(p=0.85)$ (Table 2).
The baseline NRS score was $7.64(S D=1.92)$ at week 0 and $6.81(S D=2.62)$ at week $12(p=0.16$, paired $t$-test $)$. The baseline VAS score was $72.21(S D=17.53)$ at week 0 and $65.61(S D=$ 20.53) at week 12 ( $p=0.17$, paired $t$-test). Thus, there was no "carryover" effect of prior injection on the baseline measure at week 12.

\section{Secondary Outcomes}

The percentage of responders (a 2-point change on the NRS) after 4 weeks was $58 \%$ for BTXA and $41.6 \%$ for placebo. This difference was not statistically significant $(p=0.41)$. After 12 weeks, the percentage of responders was $50 \%$ for BTXA and $41 \%$ for placebo by the NRS $(p=0.68)$, and $33 \%$ for BTXA and $41 \%$ for placebo by $20 \mathrm{~mm}$ change on the VAS ( $p=0.67)$.

Physician-rated CGI after treatment with BTXA showed a mean reduction of 5.25 points $(p=0.0087)$ for BTXA and 2.5 points for placebo $(p=0.08)$. Comparison of BTXA versus placebo showed that there was no significant difference $(p=0.20)$.

There were no differences in MDS-UPDRS parts I and II scores between BTXA and placebo 12 weeks after injections (Table 3). Although at 12 weeks after BTXA injections there was a mean increase in the MDS-UPDRS part III score of 5.27 points compared to baseline and the mean MDS-UPDRS III score decreased by 5.33 points after placebo injections, this difference was not significant $(p=0.25)$.

There were no significant differences between BTXA and placebo on total PDQ-39, or on the mobility, ADL (activities of daily living), emotional, stigma, cognition, or communication subsections of the PDQ-39 when comparing treatment with BTXA versus placebo after 12 weeks (Table 2).

Finally, we performed a logistic regression model to predict response to the treatment using the NRS after 4 weeks adjusting for age, sex, disease duration, LEDD, DBS treatment, and MDSUPDRS parts I, II and III scores, and we found no significant predictor for response to treatment with BTXA $(p=0.47)$.

\section{Adverse Effects}

No severe AEs were reported during the study. One patient reported weakness in the injected muscles in the upper limbs after treatment with BTXA (dose $=150 \mathrm{U})$, and one reported weakness in the injected muscles in the lower limbs with placebo (dose = $200 \mathrm{U})$. In both cases, the weakness resolved after 4 weeks (Pearson's $\chi^{2}=0.00, p=1.00$ ). There were no other AEs possibly or probably related to the treatment.

Table 2: Pain severity scores using NRS and VAS pre- and post-botulinum toxin A/placebo injections in PD subjects with limb pain

\begin{tabular}{c|c|c|c|c|c|c|c|c|c}
\hline & \multicolumn{3}{|c|}{ Time of Injections, mean $(\boldsymbol{S D})$} & \multicolumn{3}{c|}{ After 4 weeks, mean $(\boldsymbol{S D})$} & \multicolumn{3}{c}{ After 12 weeks, mean $(\boldsymbol{S D})$} \\
\hline & Average & BTXA group & Placebo group & BTXA group & Placebo group & $\boldsymbol{p}$ value* & BTXA group & Placebo group & $\boldsymbol{p}$ value* \\
\hline NRS & 7.64 & 7.5 & 7.79 & 5.75 & 6.62 & 0.7 & 6.62 & 7 & 0.88 \\
\hline & $(1.92)$ & $(1.78)$ & $(2.12)$ & $(2.41)$ & $(2.58)$ & & $(2.91)$ & $(2.41)$ & \\
\hline VAS & 72.21 & 72.75 & 71.66 & NA & NA & NA & 65.9 & 65.33 & 0.85 \\
\hline & $(17.53)$ & $(14.72)$ & $(20.69)$ & & & & $(18.52)$ & $(23.05)$ & \\
\hline
\end{tabular}

*Change in score between time of injection and 4 weeks, or 12 weeks postinjection between BTXA and placebo using Wilcoxon's signed-rank test ( $n=12)$. $\mathrm{BTXA}=$ botulinum toxin type A; NA = not applicable; $\mathrm{NRS}=$ numeric rating scale; $S D=$ standard deviation; VAS $=$ visual analogue scale. 
Table 3: Secondary outcomes pre- and 12 weeks posttreatment

\begin{tabular}{l|c|c|c|c}
\hline & Time of injection, mean $($ SD $)$ & \multicolumn{3}{|c}{ After 12 weeks, mean (SD) } \\
\hline CGI & & BTXA & Placebo & $p$ value* \\
\hline MDS-UPDRS I & $20.41(3.92)$ & $15.25(5.61)$ & $17.83(5.25)$ & 0.2 \\
\hline MDS-UPDRS II & $15.91(8.82)$ & $15.33(9.17)$ & $16.75(9.90)$ & 0.48 \\
\hline MDS-UPDRS III & $18.08(11.20)$ & $18.58(11.50)$ & $18.66(11.39)$ & 0.97 \\
\hline Rigidity & $29.91(13.13)$ & $35.18(23.47)$ & $24.58(11.19)$ & 0.25 \\
\hline Bradykinesia & $3.66(2.77)$ & $4.58(3.62)$ & $2.50(1.93)$ & 0.15 \\
\hline Gait and posture & $15.12(6.38)$ & $14(8.44)$ & $12.33(6.70)$ & 0.58 \\
\hline Tremor & $3.66(2.31)$ & $5.25(6.45)$ & $3.66(1.82)$ & 0.52 \\
\hline PDQ-39 & $2.25(2.50)$ & $4.16(5.63)$ & $1.41(1.62)$ & 0.34 \\
\hline Mobility & & & & \\
\hline ADL & $0.43(0.21)$ & $0.48(0.26)$ & $0.42(0.21)$ & 0.36 \\
\hline Emotional & $0.36(0.22)$ & $0.37(0.23)$ & $0.36(0.23)$ & 0.14 \\
\hline Stigma & $0.31(0.25)$ & $0.28(0.23)$ & $0.25(0.21)$ & 0.76 \\
\hline Social & $0.22(0.21)$ & $0.28(0.26)$ & $0.21(0.17)$ & 0.25 \\
\hline Cognition & $0.13(0.14)$ & $0.15(0.16)$ & $0.15(0.17)$ & 0.41 \\
\hline Communication & $0.30(0.23)$ & $0.36(0.27)$ & $0.28(0.23)$ & 0.05 \\
\hline Body discomfort & $0.22(0.21)$ & $0.30(0.24)$ & $0.21(0.21)$ & 0.07 \\
\hline
\end{tabular}

*Change in score between time of injection and 12 weeks postinjection between BTXA and placebo using Wilcoxon's signed-rank test $(n=12)$.

CGI = Clinical Global Impression; PDQ-39 - Parkinson's disease questionnaire; MDS-UPDRS - Movement Disorder Society

Unified Parkinson's disease Rating Scale (I: Non-Motor Aspects of Experiences of Daily Living, II: Motor Aspects of Experiences of Daily Living, III: Motor examination); BTXA - Botulinum Toxin type A; ADL - activities of daily living; $S D=$ standard deviation.

\section{DISCUSSION}

This study is the first double-blind randomized placebocontrolled crossover trial to assess the utility of targeted BTXA injections for painful limbs in advanced PD patients. Overall, our study showed a mild reduction in pain after 4 weeks compared to placebo, but the effect size was small and nonsignificant. Importantly, there were no significant AEs in this advanced PD population.

To understand these results, it is important to consider that we included all types of PD pain (rigidity, dystonic, and nonspecific pain). When analyzing each individual response, some participants showed a dramatic reduction in pain with BTXA, and some showed no effect at all (Table 4). We performed a subgroup analysis and found that those patients with dystonic-type pain had better (although nonsignificant) responses (reduction of 2.66 points on the NRS after 4 weeks) than those with musculoskeletal pain (reduction of 1.41 points on the NRS after 4 weeks). This suggests that pain in limb dystonia may be a better target for BTXA compared to musculoskeletal pain in PD. No other disease factors appeared to predict response to treatment.

A common AE of BTXA is transient muscle weakness. Of note, only two subjects reported mild weakness (one after BTXA treatment and the other after placebo). The motor UPDRS scores were evaluated at the in-clinic visits at the 12-week timepoint after injections at, as such, the end of the dose effect. Despite this, the lack of worsening is encouraging in terms of safety of use of BTXA in this advanced PD population.
There are several limitations of the study. At the time of our study, there was a lack of an instrument to objectively measure pain specifically in the PD population, and thus the lack of effect may reflect a lack of being able to accurately capture and measure pain unique to PD. The NRS and VAS are validated scales used for general pain but are not specific for PD. ${ }^{23}$ Following completion of our study, a new scale, the King's Parkinson's Disease Pain Scale, was internationally validated. Further studies using this rating scale would be useful. ${ }^{24}$ Our study sample size was small, though the power analysis suggested 12-14 total subjects. However, subgroup analysis (dystonia vs. musculoskeletal type pain) analysis was insufficiently powered. The absence of predictors for the response to treatment with BTXA in our study is probably related to the reduced sample size. Furthermore, the study duration may have been too short. The duration of treatment was limited to one injection and evaluation at 4 and 12 weeks. In dystonia, in general, patients often require repeated injections to notice a clinically meaningful benefit. As such, further cycles of BTXA may be required to achieve a statistically significant effect.

Pain in PD continues to be a challenging problem. There have been few double-blind placebo-controlled trials evaluating therapies specifically for PD pain. A recent multicenter trial for oxycodone plus naloxone also failed to identify an effect on pain in these patients. ${ }^{14}$

Our study shows that BTXA is safe in patients with limb pain and advanced PD; however, we failed to show a significant effect 
Table 4: Participants' individual response to treatment

\begin{tabular}{|c|c|c|c|c|c|c|c|c|c|c|c|c|c|c|c|c|}
\hline \multirow[b]{3}{*}{ No. } & \multirow[b]{3}{*}{$\begin{array}{l}\text { Age, } \\
\text { years }\end{array}$} & \multirow[b]{3}{*}{ Sex } & \multirow[b]{3}{*}{$\begin{array}{c}\text { Disease } \\
\text { duration, years }\end{array}$} & \multirow[b]{3}{*}{ Type of pain } & \multicolumn{6}{|c|}{ BTXA } & \multicolumn{6}{|c|}{ Placebo } \\
\hline & & & & & \multicolumn{3}{|c|}{ NRS (points) } & \multicolumn{2}{|c|}{ VAS $(\mathbf{m m})$} & \multirow[b]{2}{*}{ Adverse events } & \multicolumn{3}{|c|}{ NRS (points) } & \multicolumn{2}{|c|}{ VAS (mm) } & \multirow[b]{2}{*}{ Adverse events } \\
\hline & & & & & Baseline & 4 weeks & 12 weeks & Baseline & 12 weeks & & Baseline & 4 weeks & 12 weeks & Baseline & 12 weeks & \\
\hline 1 & 68 & Male & 26 & Dystonic & 7 & 4 & 7 & 62 & 72 & No & 8 & 7.5 & 7 & 73 & 62 & No \\
\hline 2 & 60 & Male & 13 & Musculoskeletal & 9 & 8 & 10 & 89 & 97 & No & 10 & 6 & 6 & 97 & 55 & No \\
\hline 3 & 80 & Male & 10 & Musculoskeletal & 9 & 9 & 10 & 88 & 85 & No & 10 & 5 & 8 & 85 & 65 & No \\
\hline 4 & 79 & $\begin{array}{c}\text { Fem- } \\
\text { ale }\end{array}$ & 14 & Musculoskeletal & 8 & 7 & 7.5 & 74 & 72 & No & 7.5 & 10 & 10 & 72 & 94 & No \\
\hline 5 & 65 & $\begin{array}{c}\text { Fem- } \\
\text { ale }\end{array}$ & 10 & Dystonic & 8 & 6 & 4 & 85 & 32 & No & 4 & 8 & 8 & 32 & 85 & $\begin{array}{c}\text { Mild weakness } \\
\text { in lower limb }\end{array}$ \\
\hline 6 & 58 & Male & 29 & Dystonic & 6 & 4 & 4 & 62 & 41 & No & 4 & 0 & 2 & 41 & 10 & No \\
\hline 7 & 66 & Male & 16 & Dystonic & 10 & 7 & 7 & 85 & 60 & No & 7 & 7 & 10 & 68 & 85 & No \\
\hline 8 & 45 & $\begin{array}{c}\text { Fem- } \\
\text { ale }\end{array}$ & 8 & Dystonic & 8 & 5 & 5 & 72 & 61 & No & 8 & 8 & 8 & 74 & 72 & No \\
\hline 9 & 70 & Male & 14 & Musculoskeletal & 7 & 8 & 9 & 78 & 78 & No & 8 & 8 & 7 & 69 & 78 & No \\
\hline 10 & 59 & Male & 8 & Dystonic & 8 & 5 & 8 & 76 & 68 & No & 10 & 6 & 8 & 92 & 76 & No \\
\hline 11 & 62 & $\begin{array}{c}\text { Fem- } \\
\text { ale }\end{array}$ & 15 & Musculoskeletal & 7 & 0 & 0 & 64 & NA & $\begin{array}{c}\text { Mild weakness } \\
\text { in upper limb }\end{array}$ & 10 & 9 & 7 & 99 & 64 & No \\
\hline 12 & 78 & Male & 15 & Musculoskeletal & 3 & 6 & 8 & 38 & 59 & No & 7 & 5 & 3 & 58 & 38 & No \\
\hline
\end{tabular}


when compared to placebo. Further studies may be focused on evaluating the longer-term effects of BTXA, particularly in dystonic pain. It is most important to continue the search for other therapeutic alternatives for patients with musculoskeletal pain.

\section{ACKNOWLEDGMENTS}

Veronica Bruno was a recipient of an American Academy of Neurology, American Brain Foundation, and Allergan Clinical Research Fellowship to work on this study. The study was supported by internal funding. Product support [botulinum toxin type A $\left(\mathrm{BOTOX}^{\circledR}\right)$ ] was provided by Allergan.

\section{DisClosures}

Maria Eliza Freitas, Deborah Mancini, and Jane P. Lui hereby declare that they have no conflicts of interest to disclose.

Janis Miyasaki has the following disclosures: Allergan: CO PI research grant, grant recipient; PCORI: Sub PI research grant, grant recipient; Parkinson Canada: supervisor-research grant, grant recipient.

Susan H. Fox has the following disclosures: Acadia: personal fees, consulting work; Britannia: personal fees, consulting work; $\mathrm{C} 2 \mathrm{~N}$ : personal fees, consulting work; Orion: personal fees, consulting work; Adamas: principal investigator, research grant; Zambon: personal fees, consulting work; Cynapsus: principal investigator, research grant; Kyowa: principal investigator, research grant.

\section{REFERENCES}

1. Ford B. Parkinson disease. Pain in Parkinson disease: the hidden epidemic. Nat Rev Neurol. 2009;5(5):242-3.

2. Beiske AG, Loge JH, Rønningen A, Svensson E. Pain in Parkinson's disease: prevalence and characteristics. Pain. 2009;141(1-2): 173-7.

3. Rahman S, Griffin HJ, Quinn NP, Jahanshahi M. Quality of life in Parkinson's disease: the relative importance of the symptoms. Mov Disord. 2008;23(10):1428-34.

4. Silva EG, Viana MA, Quagliato EM. Pain in Parkinson's disease: analysis of 50 cases in a clinic of movement disorders. Arq Neuropsiquiatr. 2008;66(1):26-9.

5. Roh JH, Kim BJ, Jang JH, et al. The relationship of pain and healthrelated quality of life in Korean patients with Parkinson's disease. Acta Neurol Scand. 2009;119(6):397-403.

6. Miyasaki JM. Treatment of advanced Parkinson disease and related disorders. Continuum (Minneap Minn). 2016;22 (4 Movement Disorders) 1104-16.

7. Geroin C, Gandolfi M, Bruno V, Smania N, Tinazzi M. Integrated approach for pain management in Parkinson disease. Curr Neurol Neurosci Rep. 2016;16(4):28.

8. Perez-Lloret S, Rey MV, Dellapina E, Pellaprat J, Brefel-Courbon C, Rascol O. Emerging analgesic drugs for Parkinson's disease. Expert Opin Emerg Drugs. 2012;17(2):157-71.
9. Schrag A, Sauerbier A, Chaudhuri KR. New clinical trials for nonmotor manifestations of Parkinson's disease. Mov Disord. 2015; 30(11):1490-504

10. Djaldetti R, Yust-Katz S, Kolianov V, Melamed E, Dabby R. The effect of duloxetine on primary pain symptoms in Parkinson disease. Clin Neuropharmacol. 2007;30(4):201-5.

11. Rascol O, Zesiewicz T, Chaudhuri KR, et al. A randomized controlled exploratory pilot study to evaluate the effect of rotigotine transdermal patch on Parkinson's disease-associated chronic pain. J Clin Pharmacol. 2016;56(7):852-61.

12. Pellaprat J, Ory-Magne F, Canivet C, et al. Deep brain stimulation of the subthalamic nucleus improves pain in Parkinson's disease. Parkinsonism Relat Disord. 2014;20(6):662-4.

13. Kim HJ, Paek SH, Kim JY, et al. Chronic subthalamic deep brain stimulation improves pain in Parkinson disease. J Neurol. 2008;255(12):1889-94.

14. Trenkwalder C, Chaudhuri KR, Martinez-Martin P, et al. Prolongedrelease oxycodone/naloxone for treatment of severe pain in patients with Parkinson's disease (PANDA): a double-blind, randomised, placebo-controlled trial. Lancet Neurol. 2015;14(12): 1161-1170.

15. Simpson DM, Hallett M, Ashman EJ, et al. Practice guideline update summary: botulinum neurotoxin for the treatment of blepharospasm, cervical dystonia, adult spasticity, and headache: Report of the Guideline Development Subcommittee of the American Academy of Neurology. Neurology. 2016;86(19):1818-26.

16. Sheffield JK, Jankovic J. Botulinum toxin in the treatment of tremors, dystonias, sialorrhea and other symptoms associated with Parkinson's disease. Expert Rev Neurother. 2007;7(6):637-47.

17. Bruno VA, Fox SH, Mancini D, Miyasaki JM. Botulinum toxin use in refractory pain and other symptoms in parkinsonism. Can J Neurol Sci. 2016;43(5):697-702.

18. Daniel SE, Lees AJ. Parkinson's Disease Society Brain Bank, London: overview and research. J Neural Transm Suppl. 1993;39:165-72.

19. Hawker GA, Mian S, Kendzerska T, French M. Measures of adult pain: Visual Analog Scale for Pain (VAS Pain), Numeric Rating Scale for Pain (NRS Pain), McGill Pain Questionnaire (MPQ), Short-Form McGill Pain Questionnaire (SF-MPQ), Chronic Pain Grade Scale (CPGS), Short Form-36 Bodily Pain Scale (SF-36 BPS), and Measure of Intermittent and Constant Osteoarthritis Pain (ICOAP). Arthritis Care Res (Hoboken). 2011;63(Suppl 11): 240-252.

20. Van Der Walt A, Sung S, Spelman T, et al. A double-blind, randomized, controlled study of botulinum toxin type A in MSrelated tremor. Neurology. 2012;79(1):92-9; doi: 10.1212/WNL. 0b013e31825dcdd9.

21. Brin MF. Dosing, administration, and a treatment algorithm for use of botulinum toxin A for adult-onset spasticity. Spasticity Study Group. Muscle Nerve Suppl. 1997;6:S208-20.

22. Grazko MA, Polo KB, Jabbari B. Botulinum toxin A for spasticity, muscle spasms, and rigidity. Neurology. 1995;45(4):712-7.

23. Kahl C, Cleland JA. Visual Analogue Scale, Numeric Pain Rating Scale and the McGill Pain Questionnaire: an overview of psychometric properties. Phys Ther Rev. 2005;10:123-8.

24. Chaudhuri KR, Martinez-Martin P, Schapira AH, et al. International multicenter pilot study of the first comprehensive self-completed nonmotor symptoms questionnaire for Parkinson's disease: the NMSQuest study. Mov Disord. 2006;21(7):916-23. 